\title{
A biblioteca pública no espaço público: estratégias de mobilização cultural e atuação sócio-política do bibliotecário
}

Elisa Campos Machado

Doutorado em Ciência da Informação. Professora Adjunto II da Universidade Federal do Estado do Rio de Janeiro - UNIRIO. Coordenadora do Sistema Nacional de Bibliotecas Públicas (SNBP).

Alberto Calil Elias Junior -

Doutor em Ciências Sociais. Professor e Coordenador do Mestrado Profissional em Biblioteconomia da Universidade Federal do Estado do Rio de Janeiro - UNIRIO.

Daniele Achilles

Professora Assistente II da Escola de Biblioteconomia - UNIRIO. Doutoranda em Memória Social na Universidade Federal do Estado do Rio de Janeiro UNIRIO.

http://dx.doi.org/10.1590/1981-5344/2263

Aborda a biblioteca pública como instituição social no espaço público, as estratégias de mobilização e o bibliotecário como agente público protagonista nesse cenário. A partir do cenário da Sociedade da Informação e do paradigma do acesso à informação apresenta e discute os conceitos e funções da biblioteca pública na atualidade e defende a presença do bibliotecário como agente público articulador local. Discute o perfil, as competências e habilidades desse profissional. Destaca os mecanismos e as estratégias que o bibliotecário pode utilizar para fomentar a mobilização da sociedade em prol das bibliotecas públicas. Conclui que é possível identificar mudanças no cenário das bibliotecas públicas no Brasil, no entanto, reafirma a necessidade de maiores investimentos intelectuais, conceituais, políticos, econômicos e culturais.

Palavras-chaves: Biblioteca Pública. Espaço público. Bibliotecário - Agente Público. Estratégias de mobilização cultural. 
Public libraries in the public sphere: librarian's strategies for cultural mobilization and sociopolitical activism

Presents the public library as a social institution in the public sphere, the strategies for cultural mobilization and the librarian as a protagonist in this scenario. Discusses the public library concepts and its functions on the information society and advocates the librarian's role as a social agent at the communities. Discusses the profile, competencies and professional skills of librarians. Highlights the procedures and strategies that could be used by the librarians to increase the mobilization in support public libraries. Concludes that there are some changes in this scenario, but marks the need for intelectual, conceptual, political, economical and cultural investiments.

Keywords: Public Library. Public Sphere. Librarian Public agent. Cultural Mobilization Strategies.

Recebido em20.11.2014 Aceito em 11.12.2014

\section{Introdução}

As bibliotecas públicas, equipamentos públicos culturais, também caracterizadas como instituições sociais, estão pautadas no paradigma do acesso à informação e da produção de conhecimento. Esta condição se estabeleceu a partir das configurações sociotécnicas que emergiram nas últimas décadas do século $X X$, marcadas, principalmente, pelas tecnologias, mas, também, pela condição de vida e trabalho da sociedade na atualidade, pautada na flexibilidade, rapidez e eficiência nos processos organizacionais. Diante desse panorama, estas instituições, assim como os profissionais que atuam nesses espaços, são convocadas ao diálogo, de uma lado com as práticas de sociabilidade que surgem a partir dessas novas configurações sociotécnicas e, de outro lado, com as práticas, chamadas "tradicionais", vigentes nas instâncias da vida social.

Em se tratando de uma instituição social a Biblioteca Pública é o resultado de determinados processos sócio-históricos e assume diversas funções, conforme o contexto no qual está inserida: memória; preservação e fomento da cultura; organização e disponibilização dos registros do conhecimento; acesso e produção de conhecimento; difusão da informação à comunidade; dentre outros. São entendidas como instituições sociais, porque servem a propósitos sociais, tais como: educação, cultura, lazer, informação, entre outros.

No entanto, no Brasil, o senso comum ainda reduz as funções sociais da biblioteca pública a um mero espaço de armazenamento de livros, acesso à leitura e de apoio à pesquisa escolar, portanto, discutir e 
entender esta instituição como um espaço público e, os profissionais que nela atuam, como agentes políticos colabora para reposicionar este tipo de equipamento cultural no cenário nacional.

Estas reflexões tiveram início durante o Seminário "A Biblioteca Pública no século XXI: lugar social, atuação política e estratégias de mobilização cultural", organizado pela Escola de Ciência da Informação, da Universidade Federal de Minas Gerais, em novembro de 2013.

\section{Biblioteca Pública no espaço público}

A busca pelo consenso em torno de um conceito ou categoria, apesar de almejada por alguns cientistas e pesquisadores, coloca-se como utópica, em particular nas Ciências Humanas e nas Ciências Sociais Aplicadas, nas quais circulam a tese de que a realidade é socialmente construída, resultado de determinadas conformações sócio-históricas (BERGER; LUCKMAN, 1979).

Hjorland (2009) assinala que as primeiras pesquisas sobre o "conceito" datam de Platão e de Aristóteles, contudo, o autor afirma que as reflexões e os debates na área de Biblioteconomia e Ciência da Informação sobre a questão ainda são incipientes. Em linhas gerais, o conceito é definido como "todo processo que torne possível a descrição, a classificação e a apreensão dos objetos cognoscíveis" (ABBAGNANO, 2007 , p. 166). Tais processos para se efetivarem, ocorrem no interior de determinadas injunções, de tal forma que os conceitos refletem "construções lógicas, estabelecidas de acordo com um quadro de referências que adquirem seu significado dentro do esquema de pensamento no qual são colocados" (MENDONÇA apud MARTINS; REIS, 2013). Ou seja, falar em um conceito (ou em uma categoria) não é tratar da essência das coisas, dos objetos, mas entender que um determinado conceito está referido a um signo e as relações que se estabelecem no entorno e a partir de um objeto ${ }^{1}$.

No que concerne ao conceito de biblioteca pública, uma análise da literatura técnico-científica da área, sinaliza na direção de algumas nuanças, que em determinados momentos apresentam-se como tensões em um campo repleto de disputas, em particular quando a análise incide sobre as funções atribuídas a, ou assumidas pelas bibliotecas públicas. Nesse sentido, constata-se que muitos foram os autores que se dedicaram ao tema ${ }^{2}$, no entanto, foge aos objetivos do presente texto realizar uma revisão de literatura. Mais do que buscar "o conceito" ou "as funções", consideramos relevante iluminar alguns pontos que emergem da análise dessa literatura.

\footnotetext{
${ }^{1} \mathrm{Na}$ definição constante do Dicionário de Filosofia de Abbagnano, assinala-se que "o problema da natureza do conceito recebeu duas soluções fundamentais" (ABBAGNANO, 2007, p. 164); uma que afirma o conceito como a essência das coisas e outra que considera o mesmo como um signo do objeto e em relação de significação com ele.

2 Apesar de considerarmos escassas as pesquisas no Brasil sobre as Bibliotecas Públicas, em relação a importância que tais instituições assumem na sociedade, ressalta-se a existência de trabalhos que vêm procurando pensar o conceito, o lugar e as funções das bibliotecas públicas na sociedade brasileira (MUELLER, 1984; FLUSSER, 1983; MEDEIROS, 2010; MILANESI, 1983, 2002 ; SILVEIRA, REIS, 2011).
} 
Susana Mueller (1984), em revisão de literatura da produção de origem anglo-saxã sobre a função social da biblioteca, assinala que ao longo dos séculos XIX e XX os conceitos de biblioteca e de biblioteca pública $^{3}$ passaram por um conjunto de transformações $e$, consequentemente, as mesmas assumiram diferentes funções, conforme o contexto social no qual estavam inseridas: a) organização dos registros gráficos; b) preservação dos registros gráficos; c) difusão da informação e do conhecimento; d) mediação da leitura e da informação; e) instituição mantenedora da ordem e do status quo; f) instituição partícipe do "processo civilizatório" g) função educacional e i) espaço para a desconstrução da ordem.

Apesar da citada revisão de literatura estar situada no tempo e no espaço, abrangendo um período que vai até finais da década de 1970 e correspondendo a uma determinada tradição - norte americana e inglesa dos estudos na área, consideramos que a mesma se configura como uma matriz para a análise em torno das funções da biblioteca pública na sociedade brasileira. Ao dirigirmos o nosso olhar para as bibliotecas públicas na contemporaneidade é possível encontrar rastros em alguns casos e permanências em outros, das funções que foram atribuídas as mesmas ao longo do século XX.

Outras funções são atribuídas as bibliotecas públicas em nossa sociedade. Medeiros (2010) aponta a biblioteca pública como um espaço de construção da cidadania, Silveira e Reis (2011) abordam as bibliotecas públicas como espaço de práticas culturais, Rasteli e Cavalcante (2013) ressaltam o lugar de mediação da leitura, Flusser $(1980 ; 1983)$ destaca a ação cultural, Silveira e Reis (2011) também evocam os lugares de memória. Como pode-se notar, são múltiplas as narrativas que surgem em torno do conceito e das funções atribuídas as biblioteca públicas em nossa sociedade.

A concepção de Biblioteca Pública na literatura da área da Biblioteconomia e da Ciência da Informação agrega a questão da construção de sociabilidade e de acesso à informação, particularmente a partir da segunda metade do século XX, em que as bibliotecas, até então pautadas pelo paradigma da posse, passaram a se estruturar, a partir de uma narrativa pautada nas transformações sociotécnicas vigentes - 0 chamado paradigma do acesso ${ }^{4}$.

Dentro deste contexto a ideia postulada por Bruno Latour (2008) surge como propícia para pensar a biblioteca pública como um espaço público. O autor identifica a biblioteca como um "centro de cálculo", ou seja, deixa de concebê-la como uma fortaleza isolada e passa a considerá-

\footnotetext{
${ }^{3}$ A autora relata que a ideia inicial do artigo era realizar uma revisão de literatura sobre a função social da biblioteca, contudo, grande parte dos trabalhos consultados referem-se à biblioteca pública.

${ }^{4}$ Para pensar bibliotecas públicas como espaço eminentemente público e de acesso à informação é necessário situar o contexto as quais essas se encontram. Portanto, é no cenário da sociedade da informação, que alvoreceu no século XXI, que este texto se coloca. O termo "Sociedade da informação" foi criado para substituir o termo "sociedade pós-industrial" ou "informacional" como denomina Castells (2000) e para expressar um novo paradigma que veio se estabelecer. Se antes, as bibliotecas encontravam-se regidas pelos pressupostos da narrativa do paradigma do acúmulo, a partir do século XXI, elas passaram a se estruturar por via de uma nova narrativa que ganhou destaque ao longo do século XX, a do paradigma do acesso.
} 
la como um nó de uma vasta rede onde circulam matérias que se transformam em signos. Ao afastar a noção de biblioteca como um espaço isolado e estático e apresentá-la como um laboratório potencializador e amplificador de inscrições, o sociólogo francês potencializa a ideia, que aqui corroboramos, da biblioteca pública como espaço cultural e informacional de acesso à leitura, à informação e à pesquisa, como lugares de encontro entre diferentes tipos de informação de saberes e de sujeitos e, também como espaço de produção de cultura e conhecimento.

É importante pontuar que para a área de Biblioteconomia e Ciência da Informação no Brasil, o Manifesto da IFLA/UNESCO sobre Bibliotecas Públicas é considerado como marco regulatório, entretanto, para além da tipologia da área, a biblioteca pública é também caracterizada pelas suas relações entre estado e sociedade civil, entre propriedade e regime jurídico público - são as chamadas bibliotecas públicas estaduais e municipais. A partir do princípio republicado de separação entre o público e o privado, a política cultural vigente defende o direito à cultura, em oposição aos privilégios de classe, ou seja, a transformação da biblioteca pública em serviço que pode ser vendido e comprado no mercado. Nesse sentido, as políticas culturais nacionais, pautadas nos princípios da cidadania cultural e do direito à cultura fomentam a criação e manutenção desse tipo de equipamento cultural pelos governos locais.

Vale esclarecer que o termo qualificador "público", aplicado as bibliotecas é utilizado também na sua concepção ampliada que desloca o "público" de um espaço institucional e delimitado ao Estado, para outro bem mais fluido, construído a partir de ações coletivas e cotidianas, que segundo Keinert (2000, p. 62), transforma este espaço em um valor compartilhado pela sociedade. Esta ampliação do conceito de "público" é evidenciada quando se afirma que todos tem o direito ao acesso à informação e ao conhecimento e devem respeitá-lo e colaborar para a sua preservação, ampliação, difusão e produção. Aqui o "público" é o resultado do entrelaçamento Estado-Sociedade e de um processo coletivo de fortalecimento da noção de cidadania (KEINERT, 2000, p. 62) e, nesse caso a biblioteca pública não se restringe a instituição estatal, propriedade que faz parte integrante do Estado. Estas bibliotecas se reconhecem como espaços públicos de cultura e educação e são criadas e mantidas por pessoas, coletivos ou instituições privadas, sem fins lucrativos, comprometidas com suas comunidades.

Neste sentido, entender a biblioteca pública como um espaço que é público, é mais do que nunca, considerar que a mesma é o resultado de um conjunto de relações que convergem para a conformação desse espaço. As bibliotecas públicas, não são espaços vazios nos quais indivíduos e coisas (registros gráficos do conhecimento, em particular) são alocados para atender a determinadas funções que a elas são atribuídas, mas o resultado de um conjunto de relações entre elementos (sujeitos e objetos) que conformam uma espécie de configuração, repleta de conflitos e tensões, em que os papéis atribuídos a biblioteca pública, enquanto uma instituição social, e as apropriações que os diversos sujeitos fazem desses espaços estão em constante diálogo. 


\section{O bibliotecário como agente público}

Independente dos paradigmas estabelecidos na área e em suas épocas é importante levar em consideração que são as pessoas e suas práticas cotidianas que fazem com que as instituições se configurem efetivamente como espaços públicos. Nesse sentido, vale lembrar que no início do século XIX, Antonio Panizzi, que atuou como bibliotecário no Museu Britânico, na Inglaterra, já demonstrava sua preocupação social ao dedicar esforços no desenvolvimento de catálogos desse museu; segundo Battles (2003), para Panizzi o catálogo era considerado um instrumento de transformação social.

Machado (2008), aponta Melvin Dewey, Paul Otlet e La Fountaine como referências, na Biblioteconomia moderna, de profissionais que atuaram e desenvolveram instrumentos de controle da informação com vistas a ampliar seu acesso dentro de um pensamos humanista e com uma função social, porém, não podemos esquecer que aquele era o momento da ciência moderna, totalmente baseada na estrutura do conhecimento, e mais, com o foco no controle e não na transferência da informação. O pensamento complexo e a concepção sistêmica do conhecimento não eram ainda considerados naquele tempo.

Com base nos relatos de experiência e da história da Biblioteconomia, tanto nos Estados Unidos da América (EUA) como na Inglaterra, percebemos que a preocupação dos bibliotecários com as questões sociais são antigas. Nesses países, os governos, ou as organizações da sociedade civil, criaram movimentos nacionais de luta contra a pobreza, o analfabetismo e a exclusão, e, os bibliotecários, bem ou mal, se organizaram e se envolveram nesses movimentos, na maioria das vezes apoiados por políticas públicas que garantiram sua participação. Apesar das guerras e das grandes recessões por que passaram muitos dos países do Norte, de modo geral, sempre houve uma reversão impulsionada pelos órgãos governamentais e as bibliotecas públicas, nesses momentos, somavam seus esforços criando serviços específicos para públicos considerados em situação de desvantagem - pobres, desempregados, pessoas com necessidades especiais, mulheres, crianças, homossexuais, enfim, grupos minoritários ou em condições de risco.

Diferentemente de outros países, no Brasil, apesar dos altos índices de analfabetismo e das grandes desigualdades sociais, poucas são as iniciativas que colocam as bibliotecas públicas como espaços de informação e apoio ao cidadão em situação de desvantagem. Pesquisas evidenciam a ausência de serviços de informação a comunidade em bibliotecas públicas e destacam que a função principal das bibliotecas públicas é a promoção da leitura para o público infantil, a oferta de espaço de estudos para o público jovem, além de empréstimo de livros e, em municípios de grande porte, o acesso à internet. Com menor ênfase, apontam a função de preservação da memória, difusão da herança cultural e estímulo a promoção literária local (CENSO..., 2010; ESTUDO..., 2013; SISTEMA..., 2013). 
Atualmente, destacam-se nesse cenário iniciativas que podem ser consideradas recentes como do Governo do Estado do Rio de Janeiro, com as Bibliotecas Parques da Rocinha e Manguinhos, ambas construídas em zonas de exclusão na cidade do Rio de Janeiro, as iniciativas do Governo do Estado do Acre que tem investido fortemente na construção e qualificação das bibliotecas públicas estaduais, assim como o Governo do Estado de São Paulo, com o investimento na Biblioteca de São Paulo, localizada no parque da Juventude, na área da antiga Casa de Detenção do Carandiru, na cidade de São Paulo. Não podemos deixar de mencionar também a histórica e reconhecida iniciativa do governo municipal de São Paulo, com o Sistema Municipal de Bibliotecas que integra mais de 105 bibliotecas públicas na cidade. Todas estas experiências são consideradas referencia em espaço, acervo, serviços, atendimento e programação cultural de qualidade, acesso local e a distância, assim como no que tange a gestão desses equipamentos públicos.

Vale ressaltar, que além dessas experiências, muitos governos locais, de municípios de pequeno e médio porte no país, tem investido na resignificação de suas bibliotecas, transformado-as em verdadeiros espaços de memória, difusão, formação e produção de conhecimento, como é o caso do município de Arapiraca, no Estado de Alagoas que, segundo dados do Sistema Nacional de Bibliotecas Públicas (SISTEMA..., 2014), nos últimos 3 anos construiu 5 novas bibliotecas públicas, sendo que todas com a participação ativa da sociedade. Ademais, é importante frisar também que o país já ultrapassou o número de 6.000 bibliotecas públicas municipais e estaduais (SISTEMA..., 2014), no entanto, pesquisas apontam para a carência de profissionais formados em Biblioteconomia atuando nesse segmento de bibliotecas (CENSO..., 2010).

Dentro desse cenário, é possível confirmar que nos últimos anos houveram importantes investimentos em bibliotecas públicas no país, mas ainda há muito a fazer para garantir a permanência e expansão dessas iniciativas. Por um lado, é necessário investir na mudança da concepção de bibliotecas públicas que impera no imaginário dos governos locais $e$, por outro lado, no que tange ao profissional, é necessário uma mudança de perfil e atitude dos bibliotecários.

Nesse sentido, vale recuperar o perfil de competências, habilidades e atitudes elencadas por Rasteli e Cavalcante (2013) que servem para os bibliotecários que atuam em bibliotecas públicas, isto é: ser leitor, conhecer as teorias da leitura, valorizar as narrativas orais, viabilizar o acesso à informação em seus diferentes suportes, desenvolver a advocacy em bibliotecas públicas, conhecer as políticas públicas para o livro e a leitura, estar atendo às multiplicidades culturais, estabelecer relações afetivas com o leitor, trabalhar em equipe, estabelecer parcerias, ter competências aplicadas às Tecnologias de Informação e Comunicação (TICs), conhecer ferramentas da Web 2.0 e, por fim, buscar a educação continuada.

A essas competências e habilidades, acreditamos que deve se somar a condição de agentes públicos e ser político, ou seja, daquele que articula o trabalho cultural com as demandas de informação da comunidade local, 
enfrentando as contradições, os conflitos que constituem as histórias daquela coletividade. Victor Flusser (1980, p. 137) há mais de 20 anos, já alardeava que "ser bibliotecário em uma biblioteca verdadeiramente pública é desenvolver de uma maneira política a sua profissão".

\section{Mobilização e estratégias de atuação do bibliotecário}

Falar de mobilização é falar de articulação local e protagonismo. O bibliotecário pode lançar mão de vários mecanismos para atuar de maneira estratégica e fomentar a mobilização da sociedade a favor das bibliotecas públicas e, uma interessante fonte de informação é o Manual das Pessoas que Advogam pelas Bibliotecas, traduzido para o português do Library advocat's Handbooks, da American Library Association (ALA), que orienta os bibliotecários na elaboração de um plano de ação local para mobilizar a comunidade.

Além disso, a aproximação com a comunidade e a implementação de práticas participativas são determinantes para que a população local se aproprie efetivamente da biblioteca pública e a reconheça como um espaço público resultante de uma ação coletiva e não somente com uma localização institucional. Para isso o bibliotecário pode começar propondo a comunidade a constituição de um Conselho da Biblioteca formado por representantes de usuários/leitores, de movimentos sociais e associações do bairro, assim como funcionários da biblioteca.

Vale lembrar que a sociedade brasileira já tem experiências reconhecidas internacionalmente relacionadas a gestão participativa, e encontra-se mais preparada para assumir responsabilidades, participar efetivamente de processos de decisão e utilizar mecanismos de controle social, como afirma Boaventura de Souza Santos (2005) em seu livro Democratizar a democracia: os caminhos da democracia participativa.

Sem dúvida alguma, as parcerias e o trabalho cooperativo são determinantes no mundo de hoje. Por exemplo, é imprescindível o trabalho em rede entre bibliotecas, sejam bibliotecas públicas, comunitárias, escolares, especializadas, ou universitárias. Nos pequenos municípios, o estabelecimento de um trabalho em rede entre bibliotecas de diferentes tipologias pode ser a solução para a sobrevivência e recolocação da biblioteca pública no cenário regional. Já em municípios maiores, a constituição de Sistemas Municipais de Bibliotecas Públicas poderá garantir a economia de recursos, a agilidade no atendimento, a otimização de acervos e serviços, entre outros benefícios.

Outro elemento importante é a apropriação e uso das Tecnologias de Informação e Comunicação (TICs), ferramentas que auxiliam o bibliotecário na aproximação com o seu público principal. De fato, ainda não é possível falar em um país incluído digitalmente (SORJ, 2008), contudo dados apontam que paulatinamente, a internet e os diversos dispositivos tecnológicos que permitem, dentre outras funcionalidades o acesso à World Wide Web, vêm se tornando parte do cotidiano de uma parcela significativa da população brasileira. De acordo com o Centro de Estudos sobre as Tecnologias da Informação e da Comunicação 
(CETIC.br), que promove periodicamente pesquisas sobre os indicadores relacionadas ao uso de tecnologias pela população brasileira, no ano de 2012, 49 \% da população brasileira são usuários da internet, o que equivale a 80,9 milhões de indivíduos.(CETIC, 2013). Se compararmos com os dados do ano de 2008, nota-se uma curva de crescimento ao longo dos últimos anos.

Figura 1- Proporção de usuários de internet

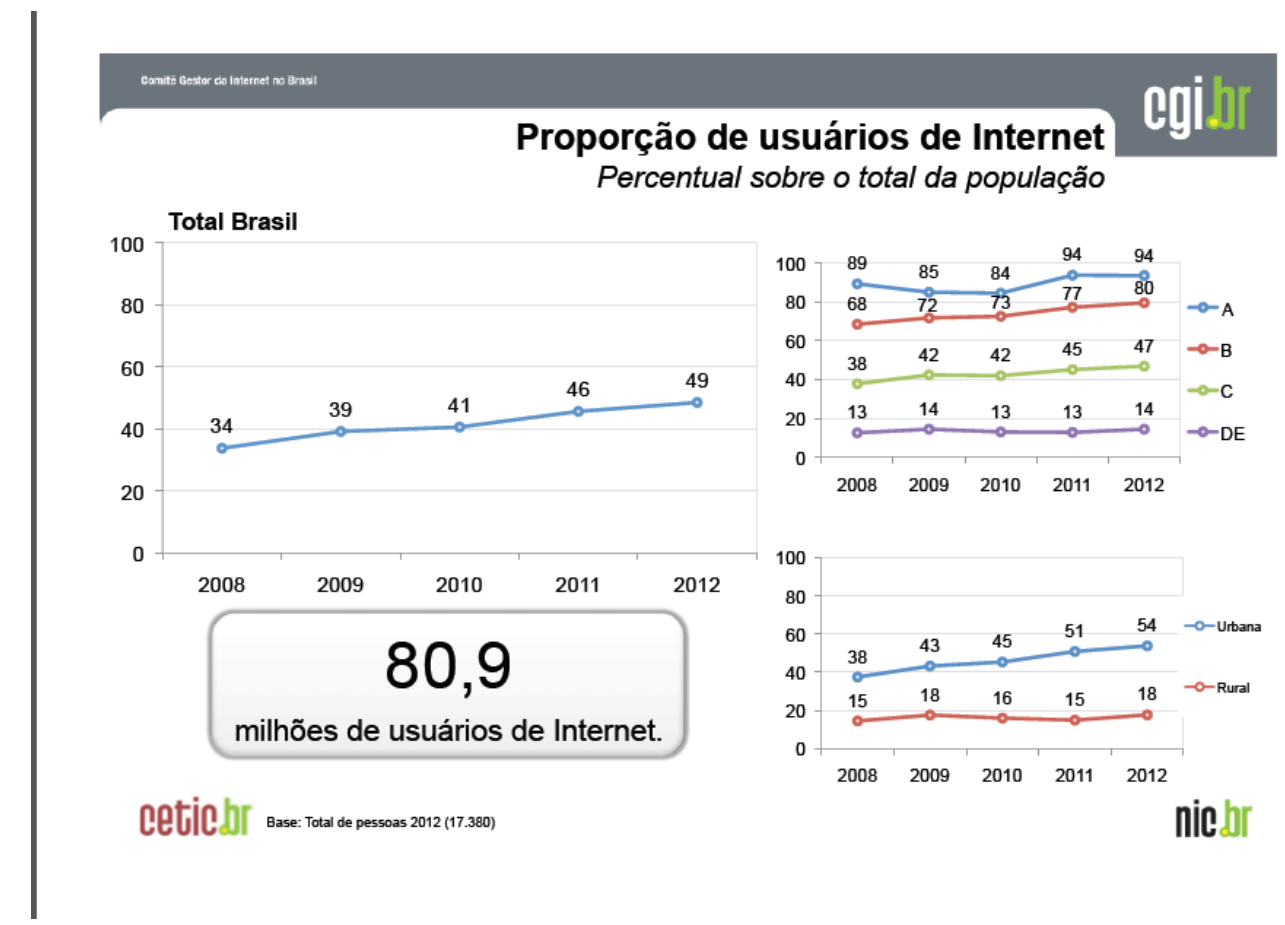

Fonte: TIC domicílios 2012.

Esse movimento, de crescente entrada no ciberespaço, denota um conjunto de oportunidades para as bibliotecas públicas. Em um primeiro momento, de aproximação com os seus usuários e principalmente com os seus não-usuários, tendo em vista a possibilidade de ocupação e de circulação por um território amplamente frequentado. De outro lado coloca-se também como oportunidade para as bibliotecas públicas se constituírem em agentes dessa ocupação, tendo em vista que o acesso à internet não garante a qualificação nos processos de busca, recuperação e uso da informação.

No âmbito estadual e nacional é determinante que os bibliotecários que atuam em bibliotecas públicas se articulem com os Sistemas Estaduais de Bibliotecas Públicas, os quais trabalham em acordo com 0 Sistema Nacional de Bibliotecas Públicas e com as políticas da área. Entre elas vale citar o Plano Nacional de Cultura (PNC) e o Plano Nacional do Livro e Leitura (PNLL).

O PNC se configura em um conjunto de princípios, objetivos, diretrizes, estratégias e metas que devem orientar o poder público na formulação de políticas culturais. Previsto no artigo 215 da Constituição Federal, o Plano foi criado pela Lei no 12.343, de 2 de dezembro de 2010, 
e tem duração de 10 anos, ou seja, ele é válido até 2 de dezembro de 2020.

Já o PNLL foi criado em 2006 e aprovado pelo Decreto Presidencial $\mathrm{n}^{\circ} 7.559$ de 01 de setembro de 2011. Construído em conjunto pelo Ministério da Cultura (MinC), Ministério da Educação (MEC) e a sociedade, constitui-se como uma política pública pautada em quatro eixos: democratização do acesso, fomento à leitura e à formação de mediadores, valorização da leitura e comunicação e desenvolvimento da economia do livro. Destacamos que o PNLL desdobra-se em Planos Estaduais e Municipais fomentando a constituição de políticas locais voltadas para a área do livro, leitura, literatura e bibliotecas e os bibliotecários precisam se apropriar desse processos e participar da implantação dos planos em seus territórios. Quanto maior a participação no processo de construção maior é a garantia de que as bibliotecas públicas estejam pautadas nesses planos.

Não podemos deixar de lado também os movimentos parlamentares a favor da leitura, da cultura e das bibliotecas. Estes são fortes parceiros para a área. Atualmente, a Câmara dos Deputados, conta com a Frente Parlamentar em Defesa das Bibliotecas Públicas, a Frente Parlamentar Mista do Livro e Leitura e a Frente Parlamentar Mista em Defesa da Cultura

\section{Considerações finais}

Pensar a biblioteca pública dentro do contexto da sociedade da informação é levar em consideração todos os elementos constituintes dessa configuração social, política, econômica e cultural, ou seja, é refletir sobre os processos relativos ao universo dessas bibliotecas no que tange sua missão, função, organização e administração.

Ademais, associar a biblioteca pública ao espaço público significa antes de tudo, pensar esse espaço como um lugar que não se configura como um espaço institucional privado, estático ou simplesmente delimitado pelo Estado, mas sim, um espaço de sentido,de sociabilidade, dinâmico, fluido, compartilhado, que se constrói a partir de ações coletivas.

A ideia de espaço público compartilhado nos ajuda a reafirmar a máxima de que todos devem ter acesso à informação e ao conhecimento, e consequentemente a produção de novos conhecimentos, a exemplo, de muitas bibliotecas públicas brasileiras que se configuram como um espaço aberto, cultural e de convivência, com ampla acessibilidade,que oferecem à população uma série de serviços públicos de qualidade a comunidade local.

Sabemos que no cenário da Sociedade da informação, para que a biblioteca pública possa reunir todas as suas funções - preservação, ampliação, difusão, acesso e produção de informação e conhecimento dois pontos são evidenciados. O primeiro trata-se da necessidade de ampliar e garantir a presença de profissionais qualificados, conscientes de sua função como agente público mobilizador, integrador e protagonista 
local, nesse tipo de equipamento público cultural. E, em segundo lugar, fomentar o diálogo e a parceria entre governo e sociedade no sentido de construir conjuntamente condições que garantam e fortaleçam as políticas públicas com foco a ampliação e o fortalecimento do processo democrático de acesso à informação e a leitura para a população brasileira, por meio das bibliotecas públicas.

\section{Referências}

ABBAGNANO, Nicola. Dicionario de filosofia. São Paulo: Martins Fontes, 2007.

BATTLES, Matthew. A conturbada história das bibliotecas. São Paulo: Planeta, 2003.

BERGER, Peter L.; LUCKMANN, Thomas. A construção social da realidade: tratado de sociologia do conhecimento. Rio de Janeiro: Vozes, 1979.

CENSO Nacional de Bibliotecas Públicas: estudo quantitativo: principais resultados. Brasília: FGV, 2010. Disponível em: <http://www.cultura.gov.br/site/wp content/uploads/2010/05/microsoftpowerpoint-fgv-ap-minc-completa79.pdf>. Acesso em: 21 jun. 2010.

CHAUI, Marilena de Souza. Cultura e democracia. Crítica y emancipación Revista Latinoamericana de Ciencias Sociales, Buenos Aires, Año 1, n. 1, jun. 2008. ISSN: 1999-8104. Disponível em: <http://bibliotecavirtual.clacso.org.ar/ar/libros/secret/CyE/cye3S2a.pdf>. Acesso em: 04 ago. 2010.

ESTUDO sobre o uso de tecnologias de informação e comunicação em bibliotecas públicas no Brasil. Fundação Pensamento Digital, 2013. Disponível em: <http://ticsbps.weebly.com/index.html>. Acesso em: 15 jul. 2014.

FLUSSER, Victor. Uma biblioteca verdadeiramente pública. Revista da Escola de Biblioteconomia da UFMG, Belo Horizonte, v. 9, n. 2, p. 131-8, set. 1980.

FLUSSER, Victor. A biblioteca como instrumento de ação cultural. Revista da Escola de Biblioteconomia da UFMG, Belo Horizonte, v. 12, n. 2, p. 145-169, set. 1983 .

HJORLAND, Birger. Concept theory. Journal of the Amereican Society for Information and Technology, v. 69, n. 8, p. 1519-1563, 2009.

JACOB, Christin. Prefácio. In: BARATIN, Marc; JACOB, Christian. O poder das bibliotecas: a memoria dos livros no ocidente. 3. ed. Rio de Janeiro: Ed. UFRJ, 2008. p. 9-17.

KEINERT, Tania Margarete Mezzomo. Administração pública no Brasil: crises e mudanças de paradigmas. São Paulo, Annablume: FAPESP, 2000.

LATOUR, Bruno. Redes que a razão desconhece: laboratórios, bibliotecas, coleção. In: BARATIN, Marc; JACOB, Christian O poder das bibliotecas: a 
memoria dos livros no ocidente. 3. ed. Rio de Janeiro: Ed. UFRJ, 2008. p. 21-44.

MACHADO, Elisa Campos. Bibliotecas comunitárias como prática social no Brasil. Tese. (Doutorado)-Escola de Comunicações e Artes, Universidade de São Paulo, São Paulo, 2008.

MARTINS, Ana Amélia Lage; REIS, Alcenir Soares dos. Sobre a migração dos conceitos: uma discussão necessaria. In: ENCONTRO NACIONAL DE PESQUISA EM CIENCIA DA INFORMAÇÃO, 14., 2013. Florianópolis, 2013. Disponível em: <http://enancib2013.ufsc.br/index.php/enancib2013/XIVenancib/viewFile/ 393/240>. Acesso em: 20 jan. 2014.

MEDEIROS, Ana Ligia. Bibliotecas e cidadania, Sinais Sociais, v. 4, n. 13, maio/ago. 2010.

MILANESI, Luis. O que é biblioteca. São Paulo: Brasiliense, 1983. (Coleção Primeiros Passos, 94).

MILANESI, Luis. Biblioteca. São Paulo: Ateliê Editorial, 2002.

MUELLER, Susana P. M. Bibliotecas e sociedade: evolução da interpretação de função e papéis da biblioteca. Revista da Escola de Biblioteconomia da UFMG, v. 13, n. 1, p. 7-54, mar. 1984.

PLANO Nacional do Livro e Leitura. Caderno do PNLL. Ed. atual. 2010. Brasília, DF, 2010.

RASTELI, Alessandro; CAVALCANTE, Lídia Eugenia. A competência em informação e o bibliotecário mediador da leitura em bibliotecas públicas. Encontros Bibli: Revista Eletrônica de Biblioteconomia e Ciência da Informação, v. 18, n. 36, p. 157-180, jan./abr. 2013.

SANTOS, Boaventura de Sousa (Org.). Democratizar a democracia: os caminhos da democracia participativa. 3. ed. Rio de Janeiro: Civilização Brasileira, 2005.

SILVEIRA, Fabrício José Nascimento da; REIS, Alcenir Soares dos. Biblioteca pública como lugar de práticas culturais: uma discussão sóciohistórica. Informação \& Sociedade: Estudos, João Pessoa, v. 21, n. 1, p. 37-54, jan./abr. 2011.

SISTEMA NACIONAL DE BIBLIOTECAS PÚBLICAS - SNBP. Manual das Pessoas que Advogam pelas Bibliotecas. 2013. Disponível em: <http://snbp.bn.br/manual-das-pessoas-que-advogam-pela-biblioteca/>. Acesso em: 05 mar. 2014.

SISTEMA NACIONAL DE BIBLIOTECAS PÚBLICAS. Metas do PNC para área de biblioteca. 2014. Disponível em: <http://snbp.bn.br/metas-do-pncpara-a-area-de-bibliotecas/>. Acesso em: 05 mar. 2014.

TIC domicílios 2012: pesquisa sobre o uso das tecnologias de informação e comunicação no Brasil. Comitê Gestor da Internet no Brasil, 2013. 
Disponível em: <http://www.cetic.br/usuarios/tic/2012/analises.htm> Acesso em: 10 mar. 2014. 